\title{
Urodimento
}

REVISTA DE ESTUDOS EM ARTES CÊNICAS

E-ISSN 2358.6958

\section{Pensamento dramatúrgico do atuante no processo de criação}

Melina Scialom

\section{Para citar este artigo:}

SCIALOM, Melina. Pensamento dramatúrgico do atuante no processo de criação. Urdimento - Revista de Estudos em Artes Cênicas, Florianópolis, v. 3, n. 42, dez. 2021.

doi DOI: http:/dx.doi.org/10.5965/1414573103422021e0209

Este artigo passou pelo Plagiarism Detection Software| iThenticate 


\title{
Pensamento dramatúrgico do atuante no processo de criação
}

\author{
Melina Scialom²
}

\begin{abstract}
Resumo
Este artigo se debruça sobre a dramaturgia corporal e os mecanismos que propiciam a autonomia criativa do atuante/performer, valorizando o conteúdo somático e afetivo da corporeidade do ator/bailarino enquanto pensamento cênico corporalizado. Através do discurso da dramaturgia na dança de diferentes autores, defende-se que o pensamento cênico do intérprete-criador pode ser visto como uma atitude dramatúrgica no fazer artístico. Provinda de uma pesquisa empírica sobre a preparação corporal do artista da cena, a dramaturgia do performer é exemplificada através da prática de laboratório fundamentada nos Estudos Coreológicos (Preston-Dunlop e Sanchez Colberg, 2010), e de um processo criativo que resultou em uma obra de dança-teatro.
\end{abstract}

Palavras-chave: Dramaturgia do performer. Pensar em movimento. Treinamento. Estudos Coreológicos. Processo de criação.

\section{The dramaturgical thinking of the performer in the creative process}

\begin{abstract}
This paper articulates body dramaturgy and mechanisms that develop the performer's creative autonomy, valuing the somatic and affective content of the actor/dancer's corporeality as an embodied scenic thinking. Through dance dramaturgy discourse of different authors, it is supported that the scenic thinking of the interpreter-creator can be seen as dramaturgical attitude in the artistic making. Coming from an empirical research about performer training, the performer's dramaturgy is exemplified through laboratory practices supported by Preston-Dunlop and Sanchez-Colberg's (2010) Choreological Studies, and a creative process that resulted in a dance theatre performance.
\end{abstract}

Keywords: Performer dramaturgy. Thinking through movement. Training. Choreological Studies. Creative process.

\footnotetext{
${ }^{1}$ Revisão ortográfica e gramatical do artigo realizada por Natasha Centenaro. Doutora em Letras - Teoria da Literatura pela Pontifícia Universidade Católica do Rio Grande do Sul (PUCRS), Estágio de doutoradosanduíche e coorientação de tese na Sorbonne Université - Faculté des Lettres (França). Mestra em Letras. Bacharel em Comunicação Social - Habilitação em Jornalismo, com Curso Superior de Complementação de Estudos Certificação Adicional em Escrita Criativa (PUCRS). Professora licenciada em Letras - Língua portuguesa e respectivas literaturas (PUCRS).

2 Pesquisadora de Pós-Doutorado do Programa de Pós-Graduação em Artes da Cena, UNICAMP (bolsa FAPESP) com estágio na Utrecht University, Holanda (2016-2018) e na Concordia University, Canadá (2020). Doutora em Dança pelo Centro de Estudos da Dança/ Departamento de Dança da Universidade de Roehampton (Reino Unido, 2015). Especialista em Estudos Coreológicos (Trinity Laban, Londres, UK). Mestre em Artes Cênicas pelo Programa de Pós Graduação em Artes Cênicas/UFBA (2009). Bacharel em Dança (2004) e Licenciada em Artes (2006) pela UNICAMP. melinascialom@gmail.com

(6) http://lattes.cnpq.br/9602091455697667

(iD) https://orcid.org/0000-0001-5701-6853
} 


\section{El pensamiento dramático del actuante en el proceso de creación}

\section{Resumen}

Este artículo se centra en la dramaturgia corporal y en los mecanismos que proporcionan autonomía creativa al intérprete, valorando el contenido somático y afectivo de la corporalidad del actor/bailarín como pensamiento escénico encarnado. A través del discurso de la dramaturgia en la danza de diferentes autores, se defiende que el pensamiento escénico del intérprete-creador puede ser visto como una actitud dramatúrgica en el hacer artístico. Partiendo de una investigación empírica sobre la preparación corporal del artista escénico, la dramaturgia del intérprete se ejemplifica a través de una práctica de laboratorio basada en los Estudios Coreológicos (Preston-Dunlop y Sánchez Colberg, 2010) y un proceso creativo que dio lugar a un trabajo de danza-teatro.

Palabras clave: Dramaturgia del intérprete. Pensamiento en movimiento. Formación. Estudios coreológicos. Proceso de creación. 
Este artigo parte de uma inquietação relativa ao termo dramaturgia associado à corporeidade do intérprete-criador ${ }^{3}$ e ao processo de criação em artes cênicas; em especial, naqueles cujo soma do artista ${ }^{4}$ é um elemento essencial para a construção da obra de arte. A investigação, assim, buscou modos de ativar a corporeidade do artista da cena, averiguando como ela influencia e, por vezes, organiza o processo e a criação em si.

Nos contextos em que reina um "olhar de fora" do dramaturgo, coreógrafo ou diretor teatral, o qual observa a forma exterior do que está sendo realizado (desenho de movimento e ação cênica) e como essa traz significado para a composição ou responde ao conceito pré-estabelecido de criação, aquilo que é experienciado pelo intérprete acaba sendo, eventualmente, ignorado. Compreendo que, quando o atuante está em movimento, acontece uma produção de afetos que (in)formam sua corporeidade, trazendo intensidades particulares aos movimentos ou às ações realizadas durante o processo de criação. É, justamente, sobre a manipulação dramatúrgica desta informação somática na criação de espetáculos que me debruço neste artigo. Através de laboratórios de prática-como-pesquisa, detalhados ao longo do texto, trago como exemplo um processo criativo, no qual evidencio os procedimentos realizados para se criar uma obra de dança-teatro. O foco deste artigo, porém, não está sobre o processo criativo em si (que pode ser acessado de forma mais detalhada em Scialom, 2019), mas sobre o como a corporeidade do atuante influencia em seu fazer dramatúrgico.

Sabemos que o intérprete-criador de solos e coletivos (com criações colaborativas) já realiza, por vezes inconscientemente, uma organização dramatúrgica de seu trabalho, como explica Maria Falkembach (2009). O que buscarei neste artigo é, justamente, isolar tal atividade para, além de validar o

${ }^{3}$ Seguindo as regras gramaticais vigentes da língua portuguesa, o gênero masculino utilizado ao longo do artigo se refere a um gênero neutro. Sabemos da problemática do uso de gêneros na atualidade e também na escrita acadêmica, em especial ao admitir o masculino como sendo neutro. Porém, acreditamos que ficaria cansativo a leitura se colocássemos a opção feminina após cada sujeito e que mesmo adicionando o feminino entre parênteses, não contemplaríamos a complexidade de gêneros presente nas discussões atuais. Assim, optamos por seguir as regras vigentes da gramática portuguesa, mantendo o masculino como um suposto gênero neutro. 
processo dramatúrgico do performer, entender e facilitar estes processos, buscando, sobretudo, modos de articulá-los na atividade criativa e na preparação corporal do atuante.

\section{Da corporeidade à dramaturgia}

Entender o corpo do ator-bailarino enquanto corporeidade capaz de organizar suas ações em cena, através de seu referencial experiencial, poderia ser o primeiro passo para se ter o intérprete-criador como dramaturgista de sua obra. Ao lançar o termo corporeidade, o filósofo Michel Bernard (2001) propõe que o corpo é um simulacro de experiências vividas em constante mudança e adaptação, sendo instável, plural, dinâmico e composto de forças intensivas e vetores diversos. Para o autor, corporeidade, diferente do corpo cartesiano (separado da mente), inclui a complexidade de tudo aquilo que constitui o corpo (como, inclusive, a cultura em que está imerso, suas características étnicoraciais, sua ancestralidade e a consciência). Patrícia Caetano (2017) explica que esse termo está diretamente associado à Somática, definida como um campo de conhecimento cuja matéria corpórea passa a "ser matéria prima para a construção de um conhecimento de si e do mundo" (Caetano, 2017, p.169). Sigo junto com Caetano, considerando a Somática como um campo de práticas que fundamentam o pensamento que acontece através da corporeidade do atorbailarino, acolhendo suas experiências enquanto linguagem e material de criação. A importância da corporeidade do artista da cena e da Somática nas criações e nas pesquisas em dança não é algo novo e vem sendo amplamente investigada por pesquisadores brasileiros, como Patrícia Caetano (idem), Elisa Teixeira de Souza (2020); Ciane Fernandes (2014), Diego Pizarro e Lilian Vilela (2019), para citar alguns. Assim, este artigo se respalda sobre o campo epistemológico da Somática (como defendido por Diego Pizarro, 2020), já estabelecido, em que a corporeidade do artista se torna um referencial nos processos de criação.

Ao pensar na corporeidade do artista da cena, Vagner de Souza Vargas e Denise Marcos Bussoletti (2015) lembram que a sua identidade corpórea é influenciada por sua formação, ou seja, pelos processos educativos e 
treinamentos pelos quais passou. Para os autores, essa identidade compõe a "dramaturgia corporal" de um performer. Eles defendem que o processo de formação do artista "pode ser considerado como sendo um sistema no qual se forja sua identidade artística, se caracterizando como texto, discurso, documento de identidade, trajetória, percurso, autobiografia, etc." (Vargas; Bussoletti, 2015, p.67). Neide Neves (2008) também prevê uma dramaturgia corporal associada ao processo de formação do artista da cena, trazendo, para tanto, as propostas somáticas da Técnica Klauss Vianna como um caminho para desenvolver tal dramaturgia. Maria Falkembach (2009, p.46) acrescenta que a dramaturgia do corpo é o conjunto de "relações e tensões do corpo presente" tendo a ação como resposta corporal que atua de forma a transformar as qualidades do corpo cênico. A dramaturgia corporal seria, segundo a autora, a própria obra do atordançarino, ou seja, sua presença, seus estados corporais organizados em sua atuação cênica.

A partir dessas considerações, indago sobre as práticas corporais que possibilitam não somente desenvolver a dramaturgia corporal do intérprete inerente ao seu soma, como sugerem Vargas e Bussoleti, Neves e Falkembach, mas também, e, acima de tudo, um sistema em que o artista da cena adquira uma autonomia enquanto criador e articulador de sua obra, ou seja, no qual o ator-bailarino - ou o performer - aja dramaturgicamente ${ }^{5}$. Nesse sentido, venho desenvolvendo um interesse particular sobre a autonomia criativa do artista da cena e como ele pode desenvolver, manipular sua dramaturgia corporal, organizar/pensar seu trabalho cênico e se tornar dramaturgo de seu próprio trabalho. Tal questão se torna importante, especialmente, quando as definições mais reproduzidas de dramaturgo na dança e no teatro se referem a um olhar de fora da cena.

Em linhas gerais, na dança, o dramaturgo ou dramaturgista é aquele que trabalha em colaboração com o coreógrafo, estimulando seu trabalho criativo, questionando suas ações, realizando pesquisa teórica, entre outras atividades de aconselhamento e questionamento (Cools, 2019). Já no teatro, Patrice Pavis 
(2008, p.117) define o dramaturgo como "autor de dramas" e "conselheiro literário e teatral agregado a uma companhia teatral, a um encenador ou responsável pela preparação de um espetáculo.” Luís de Abreu (2010, p.26) explica que o dramaturgo, em termos gerais, é aquele cuja função "cabia a organização das ações, do texto, do espetáculo, por meio das rubricas e pela articulação dos conteúdos ideológicos de uma peça, e de sua forma de transmissão.”6.

Nessas acepções generalizadas, tanto no teatro quanto na dança, o dramaturgo está do lado de fora da cena e opera a partir do que ela ou ele vê do trabalho realizado pelos performers. Esse lugar vai de encontro à experiência somática de atuação do performer, que tem como referência criativa a corporalização de sua presença, de sua ação e de seus movimentos em cena. É a partir dessa perspectiva, da experiência somática com o processo de criação, que atuaria o performer-dramaturgo. Tal proposta tangencia os discursos sobre "dramaturgia do ator", de Eugênio Barba (2010), e "dramaturgia corporal" de Neves (2008), em que os autores descrevem uma dramaturgia contida na corporeidade do performer, mas não a relacionam com um pensamento cênico e com a coesão da obra, conforme farei no presente artigo.

\section{O conceito de dramaturgia}

Para aprofundar a investigação sobre a possibilidade de se ter o performer como dramaturgo, primeiramente, desenvolvo como venho articulando o conceito de dramaturgia. De acordo com Magda Romanska (2015), o conceito vem se estabelecendo e se modificando, tanto com o passar dos anos como também pelos desenvolvimentos dos fazeres artísticos oriundos de cada época. Isso quer dizer que a dramaturgia não pode ser vista como uma concepção fixa no tempo, mas que está em movimento, associando-se às necessidades criativas e aos processos de criação emergentes em cada período histórico. Para Lehmann e Primavessi (2009, p.3), as próprias necessidades

\footnotetext{
${ }^{6}$ Essas definições da função do dramaturgo, tanto na dança quanto no teatro, são visões gerais das funções desse profissional em uma produção. Porém, elas não representam o escopo do debate que vem acontecendo sobre a dramaturgia nas artes cênicas contemporâneas. Este debate será levantado na próxima seção deste artigo.
} 
técnicas, poéticas, políticas e criativas das artes cênicas contemporâneas "vêm demandando novos estilos e competências da dramaturgia." Dessa forma, ao se pensar em dramaturgia, estamos evocando um fazer que está em constante mutação. Dentro desse universo, aproximo-me às abordagens que as pesquisas e práticas em dança têm dado ao termo, justamente por propor um olhar expandido para o termo, relacionando-o à operações dramatúrgicas que não necessariamente pertencem a uma única pessoa no processo de criação.

Hansen (2015) esclarece que a dramaturgia na dança não possui uma definição clara, concisa e estabelecida; não se classificando, assim, como um campo de conhecimento fechado e delimitado por uma prática, uma técnica ou um produto artístico, literário ou teórico. Diferentemente do teatro, que possui uma definição e um campo de prática já estabelecidos para o termo e, inclusive, fixando a função de dramaturgo como uma atividade reconhecida dentro da produção teatral, a dança não apresenta nenhum desses conceitos ou dessas funções como um conhecimento tradicional. Apesar disso, muito vem sendo discutido sobre as possíveis dramaturgias da dança (Dória, 2016; Scialom; Fabrini, 2019; Macedo, 2016; Cools, 2019; Trencsényi, 2015, entre outros).

Para Katalin Trencsényi (2015), o pensamento dramatúrgico na dança apareceu junto com a visão da dança enquanto linguagem artística pertencente às artes cênicas. Foram as discussões sobre composição, assinatura coreográfica, expressão através do movimento e relação com o espectador, que revelaram como pensadores, escritores e fazedores da dança, desde a Grécia antiga, já pensavam a dramaturgia na dança. Para Trencsényi (2015), tal pensamento começou com os escritos de Lucian de Samosata, datados da metade do século Il d.C., e foi sendo revisitado por outros escritores ao longo dos séculos, como Guglielmo Ebreo de Pesaro (século XV), Balthasar de Beaujoyeulx (século XVI), Michel de Saint-Hubert (século XVII), chegando até o já conhecido Jean-George Noverre (século XVIII). Porém, o conceito em si (no contexto da dança) apareceu pela primeira vez no trabalho de Rudolf Laban (Laban, 1975) em 1935, quando o autor propôs que a dramaturgia na dança estava associada ao percurso interno e emocional do bailarino e de seu personagem, sendo um veículo de expressividade. Para fundamentar tal pensamento, Laban (1978) lançou o termo 
dance drama para designar sua práxis relativa à criação de personagens a partir de tensões produzidas pelo movimento (expressivo) do bailarino e/ou ator?.

Foi apenas na modernidade que o termo dramaturgia surgiu nos discursos da dança. Trencsényi (2015) aponta que, nesse contexto (modernismo e pósmodernismo na dança), a dramaturgia surge em determinadas colaborações artísticas entre coreógrafos e outros profissionais - em sua maioria, críticos, pesquisadores ou produtores -, apresentando, assim, um sentido "dramatúrgico" na produção da área. Segundo a autora, o termo apareceu primeiramente na colaboração entre Pina Bausch e o jornalista Raimund Hoghe no final da década de 1970. Foi somente a partir da década de 1990, que a posição de dramaturgos na dança, assim como nas artes cênicas em geral, adquiriu um papel mais central e ativo. Com isso, os fazeres contemporâneos foram remodelando o sentido e a função da dramaturgia em um espetáculo, além do próprio ofício do dramaturgo em uma produção. Os exemplos mais conhecidos são as colaborações artísticas estabelecidas pelos dramaturgos (teóricos e críticos) Marianne Van Kerkhoven, Guy Cools, André Lepecki e Heidi Gilpin junto a coreógrafos europeus e estadunidenses interessados em compartilhar o processo de criação com um "conselheiro".

As colaborações dramatúrgicas entre críticos ou dramaturgos e coreógrafos transformaram-se em atividades nas quais surgiu um indivíduo com um "olhar de fora”, que orientou o/a coreógrafo(a) a comunicar suas intenções através do corpo de bailarinos-intérpretes, oferecendo descrições de sua experiência como espectador da obra. A atuação do dramaturgo na dança passa, portanto, a estar relacionada com as atividades de dar sentido à obra e de se pensar na relação entre criação e recepção de um espetáculo. A partir dessa perspectiva, Hansen (2015) esclarece que a dança não importou simplesmente a teoria teatral dramatúrgica, mas desenvolveu sua própria atividade relacionada ao termo, levando em consideração as características primordiais desta linguagem artística, que tem sua escritura cênica nos corpos que se movem no espaço e durante o tempo da apresentação. Através de exemplos de colaborações entre dramaturgos 
e coreógrafos, Hansen (2015) defende que na dança a dramaturgia se distancia do agente dramaturgo - como acontece tradicionalmente no teatro - para se aproximar de processos de "operações dramatúrgicas", como acontecem no teatro pós-dramático. Tais processos redefinem a função da dramaturgia em uma obra, incluindo a do dramaturgo, ao apontar para a questão: o que pode a dramaturgia nos processos de criação? Ao desenvolver a mesma pergunta e o olhar sobre as operações dramatúrgicas em dança, a pesquisadora Maaike Bleeker (2003) explica que no processo criativo a dramaturgia tem um status de "pensamento", sendo uma atividade de reflexão sobre os nexos dos elementos da obra. Essa teoria lançada sobre o termo sugere uma dilatação do conceito e de suas funções no fazer artístico cênico, podendo a dramaturgia, inclusive, ser descolada da atividade de um indivíduo e existir como a organização ou a estruturação de um trabalho artístico. Nesse sentido, o dramaturgo Jeroen Peeters esclarece:

A atividade dramatúrgica nem sempre envolve o ofício efetivo de um dramaturgista; portanto, trato menos da função do dramaturgista do que da dramaturgia comum a atividade que é própria ao processo artístico. A dramaturgia ocupa-se com o desenvolvimento de um terreno comum para a produção de sentido, o que gostaria de considerar como uma responsabilidade comum a todos os colaboradores (Peeters in Caldas; Gadelha, 2016, p.178).

Gisela Dória (2016, p.197) lembra que "a dramaturgia está presente na dança ainda que não seja assim denominada, mesmo que ninguém tenha se ocupado de pensá-la e construí-la.” Portanto, a dramaturgia vai além da profissão do dramaturgo (como também do coreógrafo). Ela se revela enquanto pensamento cênico envolvendo a organização da obra como um todo - respondendo às premissas estéticas de cada momento. Por isso, o conceito de dramaturgia está constantemente em processo - respondendo ao fazer artístico de cada época.

Os autores acima citados nos revelam que as operações dramatúrgicas na dança refletem a fragmentação imanente das fronteiras presentes dentro dos processos de criação em artes cênicas, misturando, assim, o pensamento cênico (generalizando-o como o trabalho do dramaturgo) ao trabalho criativo (generalizando-o como a função primordial dos coreógrafos/bailarinos), cada vez 
mais. Outrossim, como Peeters articulou, a dramaturgia pode vir a ser responsabilidade de todos os(as) participantes de um processo criativo (como também de nenhum em particular). Portanto, o papel aparentemente intelectual (e, por vezes, teórico) do dramaturgo (recorrente no teatro e nas colaborações artísticas da dança) é dissolvido junto à prática dos performers, podendo, inclusive, ter sua função entregue ao público, como sugerem Vanessa Macedo e Sayonara Pereira (2015). Esse quadro demonstra que a função da dramaturgia e do dramaturgo no processo criativo tem se diluído nas práticas de criação dos fazedores da cena, sejam eles os atores, dançarinos, acróbatas, diretores, encenadores, iluminadores, figurinistas, escritores, conselheiros, etc.

Dentro desse panorama, em que o conceito de dramaturgia vem se atualizando junto à produção e ao pensamento contemporâneo das artes da cena, somado ao meu interesse pela experiência e corporeidade do intérprete, pergunto como o saber somático de atores e bailarinos (performers) poderia orientar e elaborar a dramaturgia de um trabalho? Se a dramaturgia está relacionada ao pensamento cênico, à provocação, à produção de sentido em sua acepção do sentir, seja no plano das sensações e sentimentos, ou no plano das ideias e dos conceitos, o que significa e como fazer dramaturgia a partir da corporeidade do artista da cena? Foi justamente para responder a essas perguntas que realizei laboratórios de pesquisa corporalizada ${ }^{8}$ e orientei a criação de um espetáculo de dança-teatro.

\section{Exercitando o pensamento dramatúrgico do performer}

Memórias é um espetáculo de dança-teatro que surgiu para experimentar um processo de criação baseado na dramaturgia realizada pelo performer. Com estreia em novembro de 2018, no Departamento de Artes Cênicas da UNICAMP, ele fez parte da busca por entender e navegar sobre o conceito e a prática da dramaturgia a partir da pesquisa de movimento e de criação de Caroline Sobolewska, Ana Flávia Felice, Guilherme Moreira e Melina Scialom. A dramaturgia

8 o uso do termo corporalizada (pesquisa corporalizada) é similar ao termo incorporar - traduções do embodied em inglês -, que significa trazer informações desde o ambiente, seja ele externo ou interno para se alojarem no corpo e formarem a corporeidade. Para mais detalhes ver Souza, 2020. 
no e do espetáculo está presente em dois momentos do processo de criação. O primeiro deles está no pensamento dramatúrgico de cada um dos performers, que exercitam a criação a partir de um pensar em movimento (detalhado adiante). Já o segundo, tem a dramaturgia enquanto elaboração da estrutura (ou escrita da cena) que formatou o espetáculo. Ao longo deste artigo, trarei estas duas perspectivas, dando ênfase ao desenvolvimento do processo dramatúrgico enquanto pensamento em movimento do performer. Considerando-se, assim, a segunda perspectiva enquanto consequência desse pensamento.

Trabalhar com a práxis labaniana associada à dramaturgia se mostrou um caminho coerente. Como apontei acima, Laban introduziu a palavra drama à dança (dance drama) para contextualizar sua pesquisa sobre o movimento expressivo e a dança-teatro (tanztheater). Para Laban (1978), a dança teatral traz uma narratividade particular ao corpo em movimento (ao invés de palavras). Sua ex-aluna, Jean Newlove (1993), explica que as tensões provindas de diferentes (combinações) dinâmicas de movimento geram conflitos, aproximando o movimento expressivo (dançado) da atividade dramática de desenvolver emoções através do contraste de diferentes estados. Nesse caso, a preocupação não está em elaborar narrativas, mas de aflorar relações humanas associadas às atmosferas criadas pela manipulação de energia e de espaço, no que Schmidt (2000 apud Fernandes, 2006, p.45) chamou de uma "dramaturgia de contrastes", característica da dança-teatro visionada por Laban e desenvolvida por seu aluno Kurt Jooss e por Pina Bausch.

Para desenvolver um pensamento dramatúrgico e em movimento, criando atmosferas de energias e contrastes, optei por trabalhar com a filosofia de Laban pela perspectiva dos Estudos Coreológicos (Choreological Studies) como plataforma para alimentar um processo de pensar em movimento. O pensar em movimento é um termo elaborado a partir da aproximação da práxis de Laban à Somática, considerando-se que o pensamento acontece através da corporeidade, ou seja, não somente na mente (cognitivo), mas pelo corpo inteiro. De acordo com Bonnie Bainbridge Cohen (2015), o pensamento (somático) está presente no corpo como um todo - onde cada uma de suas partes, órgãos e sistemas 
pensam9. Laban (1978) associou a ideia de pensar através do movimento às artes cênicas na primeira metade do século XX, quando insistiu que pensar em termos de movimento é um tipo de pensamento sem nomenclatura e oposto ao pensamento em palavras ${ }^{10}$.

Ao longo de sua vida, Laban buscou entender quais foram os princípios fundamentais que compuseram a expressividade corporal humana (ver Fernandes, 2006). Ele acreditava que o corpo possui um conhecimento encarnado, o qual é elaborado ou materializado através do movimento. De forma analítica e empírica, Laban trabalhava com colaboradores (em sua maioria, dançarinos) que the forneciam material para análise e plataforma para experimentar suas ideias. Ele chegou a uma práxis que categoriza e observa o movimento a partir de qualidades (tempo, espaço, fluxo e peso), que chamou de Eucinética, Dinâmica ou Esforços; e como o indivíduo acessa o espaço ao seu redor, que chamou de Corêutica, Espaço ou Harmonia Espacial. Essas duas categorias juntas fazem parte da Coreologia, definida como "um tipo de gramática ou sintática do movimento que lida não somente com a forma externa do movimento mas também com seu conteúdo mental e emocional” (Laban, 1966, p.vii).

Baseados na Coreologia, os Estudos Coreológicos foram desenvolvidos por Valerie Preston-Dunlop, pensando em uma forma de alinhar a práxis de Laban com o fazer artístico do final do século XX. Ou seja, ao olhar para a produção da dança pós-moderna, a autora percebeu que as duas categorias (Corêutica e Eucinética) pensadas por Laban não eram suficientes para estudar a produção artística contemporânea. Por isso, ela desenvolveu e acrescentou mais três categorias - Corpo, Ação e Relacionamento - às duas pensadas por Laban na primeira metade do século XX: Dinâmica e Espaço (Preston-Dunlop, 1980)11.

O universo contemporâneo da práxis de Laban foi, portanto, meu ponto de

${ }^{9}$ Cohen, idealizadora da prática somática Body Mind Centering, é formada em Laban Movement Analysis, tendo sido aluna de Irmgard Bartenieff, que, por sua vez, foi aluna de Rudolf Laban na Alemanha na década de 1930.

${ }^{10}$ De acordo com Martha Eddy (2018), Laban foi um dos influenciadores das práticas somáticas que surgiram no século XX

${ }^{11}$ Sobre os Estudos Coreológicos ver Scialom, 2020. 
partida. Além de perguntar o que pode a dramaturgia?, passei também a perguntar o que pode a práxis de Laban corporalizada pelo performer? ${ }^{12}$. Assim, em uma investigação de prática-como-pesquisa (Nelson, 2013), na qual a pesquisa acontece através da prática e não sobre ela, passei a realizar laboratórios para indagar sobre o quê o performer pode fazer com a Coreologia e o pensar em movimento em processos criativos cujo foco está na experiência e nas atmosferas criadas, e não na forma semântica (apreendida pelo olhar de fora).

Para conduzir os laboratórios, desenvolvi uma série de práticas, elaboradas sobre a práxis de Laban e sob uma perspectiva somática associada aos Estudos Coreológicos. Essas práticas tinham o intuito de trabalhar sobre a corporeidade do performer, auxiliando-o a aprimorar seu domínio corporal relacionado à realização de um movimento consciente e com variações expressivas ${ }^{13}$. Os exercícios visavam associar, em cada indivíduo, a cognição, a cinestesia e a percepção corporal aos afetos, às sensações e imagens que surgem no performer quando este está em movimento. Esse trabalho aconteceu durante dois anos, através de encontros semanais com três horas de duração, na forma de laboratórios de pesquisa, para incitar o pensamento somático dos performers participantes e alimentar o que o filósofo José Gil chama de um "corpo da consciência” (2018, p.110). Vejo nas palavras do filósofo Gil uma fundamentação desta proposta:

[...] ter consciência dos movimentos internos produz dois efeitos: a consciência amplia a escala do movimento, experimentando o bailarino sua direção, sua velocidade e sua energia como se tratassem de movimentos macroscópicos; e a própria consciência muda deixando de se manter no exterior do seu objeto para penetrar, o desposar, impregnar-se dele: a consciência torna-se consciência do corpo, os seus movimentos enquanto movimentos de consciência adquirem as características dos movimentos corporais. Em suma, o corpo preenche a consciência com sua plasticidade e continuidade próprias. Forma-se assim uma espécie de 'corpo da consciência': a imanência da

${ }^{12}$ Essas perguntas foram inspiradas na filosofia de Gilles Deleuze, que propõe que, ao invés de realizar questões relativas à identidade ou definição de algo, passe a se fazer perguntas funcionais ou práticas sobre "o que ela faz?" ou "como funciona?". Um interesse relativo à prática, ao uso e à função que algo exerce no mundo.

13 Neste artigo, quando utilizo a palavra movimento me refiro ao corpo em estado de presença, incluindo variações de fatores como velocidade, uso do espaço, fluência e força. 
consciência ao corpo emerge à superfície da consciência e constitui doravante o seu elemento essencial (2018, p.109).

Por exemplo, uma categoria de exercícios recorrentes que realizávamos estavam baseados nas escalas de movimento da Harmonia Espacial de Laban. Estudamos, corporalizamos e praticamos as escalas de defesa, a escala diagonal e as escalas A e B realizadas dentro da cinesfera (Laban, 1966) ${ }^{14}$. Após alguns encontros repetindo as escalas e aprendendo sobre o que pode um corpo no espaço em determinadas organizações dinâmicas, percebi - através da minha observação, das conversas durante os laboratórios e também nos relatos escritos e registrados no diário virtual coletivo ${ }^{15}$ - que os(as) participantes estavam começando a ampliar seus repertórios de movimento (relativo ao uso do espaço disponível ao redor do corpo) e também manipulando suas cinesferas em resposta aos seus anseios expressivos. Em seguida, partimos para improvisações livres sobre cada escala. Nas improvisações, as escalas se tornam um mapa de localizações que o corpo percorre e atravessa. O performer deixa de seguir a ordem harmônica (sequenciamento de locais na cinesfera a serem acessados), inicialmente proposta por Laban, e passa a se mover utilizando do corpo da consciência, guiado pelas sensações de seu movimento.

Ao corporalizar as escalas e as improvisações, insisti para que cada participante estivesse atento às sensações e às imagens que surgiam das diferentes corporeidades experimentadas. Assim, os performers passaram a realizar associações entre o uso do espaço cinesférico (ao redor do corpo), organizações corporais (abrindo, fechando, subindo, descendo, avançando, retrocedendo, torcendo, etc.), imagens, sensações e afetos, possibilitando a ampliação do corpo da consciência.

Para olhar os afetos que emergiram com o movimento, sigo com o

${ }^{14}$ A fim de estudar o movimento dos seres vivos, Laban se baseou na geometria dos cinco Sólidos de Platão: tetraedro, octaedro, cubo, icosaedro e dodecaedro. Ele utilizou a geometria destes sólidos como se fossem mapas do que chamou de cinesfera, ou seja, o espaço que o corpo ocupa através de seu movimento. Sobre a geometria destes sólidos, Laban criou exercícios chamados de "escalas", nas quais o performer considera seu corpo como se estivesse dentro de um sólido geométrico e vai se movendo em direção aos vértices deste sólido em uma ordem pré-determinada (denominada de ordem harmônica), geralmente associada à teoria da harmonia musical. As escalas A e B são sequências de movimentos realizadas na geometria do icosaedro. Ver Laban, 1966.

15 Os participantes dos encontros registravam suas impressões em um diário coletivo e salvo na plataforma Googledocs - onde todos tinham acesso. 
pensamento de Deleuze e Guattari (2004). Para Massumi (Massumi em Deleuze; Guattari, 2004), os afetos não podem ser reduzidos a uma só coisa ou definição. São intensidades "pré-pessoais" que correspondem a uma passagem de um estado experiencial do corpo para outro, influenciando a ação corporal Shouse (2005) lembra que os afetos são experiências não representacionais/semióticas das intensidades que transpassam o corpo, sendo estas pré-verbais ${ }^{16}$. Os afetos não podem ser transpostos para linguagem, justamente por serem intensidades não linguísticas e dinâmicas, que atuam quantitativamente sobre uma qualidade da experiência. Foi justamente por essa particularidade intensiva, dinâmica e processual dos afetos, que busquei trabalhar com os performers, procurando exercícios os quais pudessem ativá-los para que fosse possível reconhecê-los (mas não delimitá-los) nas intensidades no/do corpo em movimento, assim estimulando o corpo da consciência.

Na busca por gerar afetos, tomar consciência deles e passar a pensar em movimento através deles, criei exercícios a partir da exploração de combinações de qualidades de movimento (ver Laban, 1978); exploração de frases rítmicas, estruturas de relacionamento (ver Preston-Dunlop, 1980) e de escalas (ver Laban, 1966); sempre voltando a atenção para entender de que modo as variações expressivas originadas nas práticas geravam intensidades afetivas no performer. Por exemplo, um dos exercícios foi estudarmos em duplas as estruturas de relacionamento como toque, aproximação, distanciamento, agarrar, rodear, deslizar com ou sem toque, foco e se debruçar. Na primeira etapa, em grupos com três integrantes, duplas improvisaram sobre esses elementos enquanto a terceira pessoa assistia. Após diversas trocas entre os que se relacionavam e quem assistia, aquele com o olhar de fora passou a dar indicações de como a dupla deveria interagir, passando, assim, a manipular a relação desta dupla. Tais indicações partiam das memórias das relações experimentadas anteriormente e do desejo de materializar sua memória no corpo do outro. Ao final do exercício, houve um tempo para a troca de experiências e conversa (como acontecia em todos os encontros). Sobre esse exercício, uma das participantes relatou ter

\footnotetext{
${ }^{16}$ Ao me referir às experiências não representacionais, sigo junto com a teoria de Deleuze e Guattari, 2004) de que afeto não é da ordem do pensamento mental ou intelectualização representacional, e muito menos um dado subjetivo mas sim uma outra variedade de informação, que se aproxima do movimento e da intensidade ou estados intensivos.
} 
percebido a diferença entre a sensação interna de realizar movimentos e a observação de outra dupla realizando a proposta, salientando a importância de tanto observar quanto realizar fisicamente o exercício.

Outra participante escreveu sobre a prática com escalas:

Ao realizar a escala no cubo, primeiro fiquei perdida, mas depois fui entendendo onde estavam os pontos no espaço, para onde precisava me dirigir. A repetição destes movimentos e escala foi importante para que meu corpo aprendesse e eu não precisasse mais pensar para onde deveria ir. O corpo vai sozinho. (Fala de participante do grupo registrada no diário de bordo durante encontros do grupo de pesquisa).

Podemos perceber, nas palavras das performers, que, ao experimentarem as propostas, elas ativaram o corpo da consciência, passando a investigar a relação entre movimento/imagem/sensações e os afetos emergentes. Após corporalizar os princípios de movimento (como os de relacionamento e espaço revelados acima), a corporeidade passa a agir em conexão direta com as imagens e sensações emergentes, trazendo a impressão de que "o corpo vai sozinho". Junto com Silva Junior e Machado (2020, p.45765), percebemos, neste trabalho, a possibilidade das imagens serem um dispositivo do corpo, sendo "pensadas como atributos geradores de afetos." Tal percepção seria a própria formação de um corpo da consciência.

Ativando o corpo da consciência, começamos a construir pequenas células coreográficas vindas da memória somática de improvisações que fizemos em laboratório. Foi através dessas composições que observei como os performers memorizavam partes do que improvisavam para, em seguida, repeti-las, a partir dos princípios que estavam usando (dentro das categorias Corpo, Espaço, Dinâmica, Ação e Relacionamento). Percebi também como passaram a se mover não através de ideias, mas de afetos e imagens (individuais de cada um) que surgiam ao se movimentarem. Nessas práticas, sempre dividi o grupo para que pudéssemos todos experimentar e observar, ativando tanto a atenção e as sensações geradas naquele que realiza a ação, quanto os afetos e imagens geradas naquele que assiste - o olhar de fora. Nesse processo, a Coreologia foi se tornando uma linguagem de análise ou uma "análise em movimento", como 
propõe Fernandes (2014). Para a pesquisadora (Fernandes, 2014, p.85), esse termo reflete uma

...transformação epistemológica radical, pois o objeto de análise passa a ser o modus operandi de todo o processo, ou seja, torna-se sujeito ativo de sua própria história, desconstruindo maneiras de dominação sobre ele (no caso, nós, seres vivos, constituídos de pulsação) em um processo dinâmico de pesquisa.

Ao mesmo tempo, ao alimentar a consciência do corpo e o corpo da consciência, a análise em movimento se tornou uma ponte para os afetos que surgiam quando os performers corporalizavam fraseados distintos ${ }^{17}$. Nesse registro, os performers operavam de acordo com suas experiências e concomitantemente com (um corpo da) consciência do que estavam fazendo enquanto faziam. Estavam, portanto, pensando-em-movimento e articulando suas ações de acordo com tal pensamento.

Dos diversos dispositivos que motivaram as improvisações e os exercícios de composição, optamos por aprofundar a pesquisa sobre as memórias. Percebemos que elas, ao serem ativadas durante as improvisações, evocavam determinadas imagens e afetos. Iniciamos, então, um processo de criação para testar como o pensamento, na forma de movimento e intensidades afetivas, atua numa composição cênica. O intuito desse experimento foi possibilitar aos performers agir como intérpretes, pensadores e articuladores criativos, que estariam atuando de forma dramatúrgica durante o processo. Assim, nasceu o espetáculo Memórias.

17 Fraseado é um termo da práxis de Laban que se refere ao conjunto de movimentos organizados sequencialmente que devem ser realizados de forma contínua do início ao fim. Quando executado dessa forma, o fraseado traz uma dinâmica ou expressão rítmica ao conjunto de movimentos. 


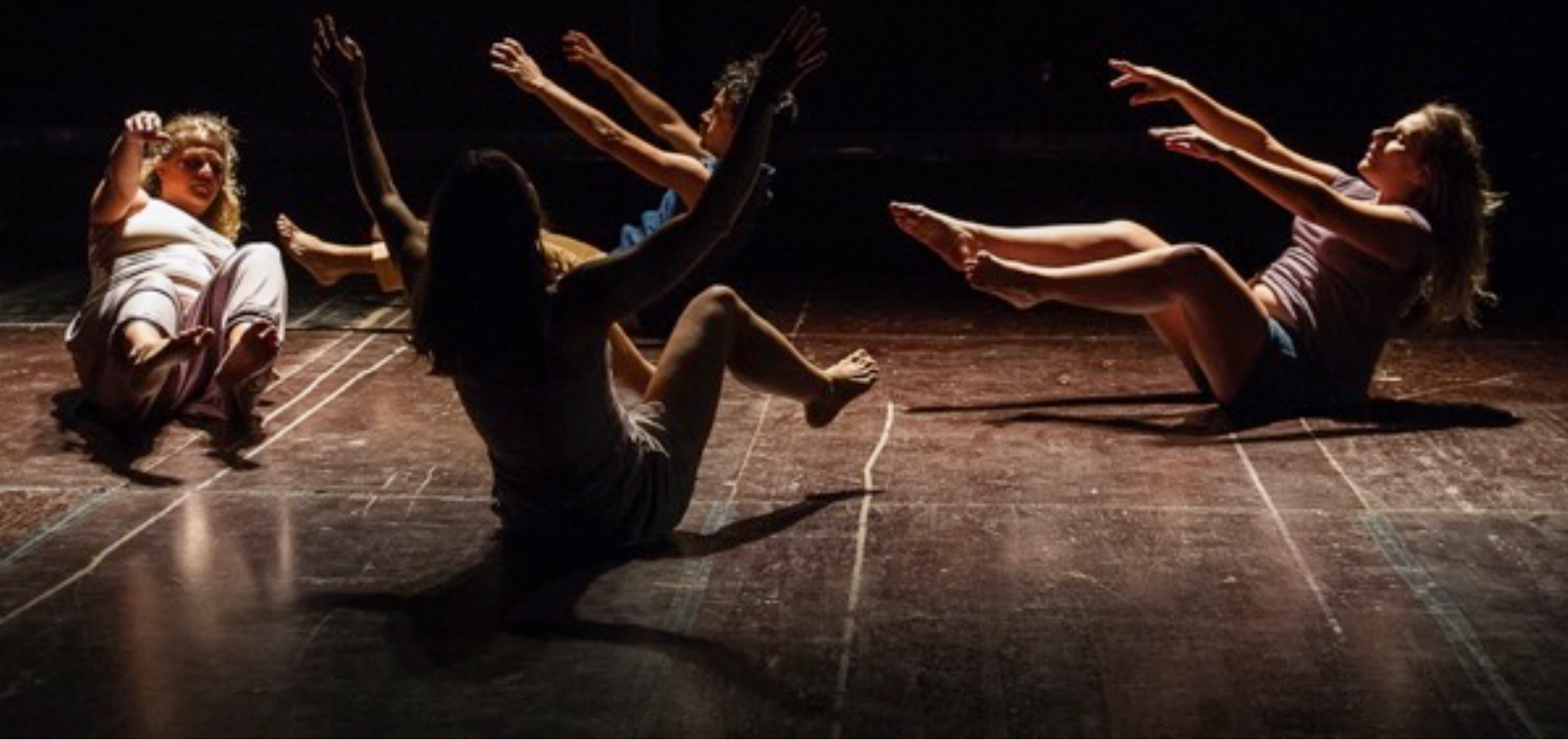

\section{A dramaturgia do performer em prática}

Decidimos partir de memórias pessoais dos performers para criar o que chamamos de matrizes, ou seja, fraseados ou sequências coreográficas ${ }^{18}$. Elas variavam de três a cinco minutos cada, compostas (ou estimuladas) a partir da

${ }^{18}$ Apesar do termo matrizes ser amplamente utilizado no teatro para designar ações físicas (Ferracini, 2009), pontos de partida, referências artísticas, teatrais e extra-teatrais de uma ação ou criação cênica (Bonfitto, 2002), por exemplo, neste processo criativo, especificamente, matrizes se referem a uma mistura entre os elementos citados e fraseados ou "células coreográficas" (um termo que também é amplamente utilizado na dança para designar pequenas sequências de movimento). 
transposição de lembranças, algo imaterial e abstrato, para o corpo em movimento no tempo e espaço. Buscávamos a relação entre memória, afetos e imagens, e como poderíamos articular essa relação na cena. Isso porque, nos interessavam as lembranças que não são descritas de maneira linguística ou reflexiva, mas que surgem em nossa consciência pelo veículo dos afetos, das imagens e do corpo em "modo de consciência" (Gil, 2018, p.110).

Com relação às imagens que surgem na consciência do performer quando seu corpo está em movimento, volto a me aproximar ao pensamento de Gil, em paralelo aos estudos da pesquisadora da dança Adriana Bittencourt. Ao realizar um estudo aprofundado sobre as imagens na dança, Bittencourt (2012) explica que elas emergem como modos de percepção do bailarino de seu próprio corpo em ação, estando assim diretamente relacionadas ao movimento. Na mesma linha, Gil (2018), ao estudar o trabalho e o discurso do bailarino de Steve Paxton, conclui que as imagens se aderem ao movimento, não sendo apenas representações mentais, mas comprometem também o corpo material, ou seja, como ele se move. O autor lembra que, para os bailarinos, as imagens trazem sensações reais de peso, tensão e velocidades. Isso quer dizer que o movimento gera imagens, e essas, em resposta, influenciam o movimento do corpo, em um processo de retroalimentação constante. Se Greiner (2005, p.116) considera o “movimento, fluxo de imagens, ação movida por um propósito" como pensamento; então, sugiro que, ao se mover operando sobre imagens e afetos, estamos pensando em movimento, com o propósito de criar uma obra de dançateatro através de nossas memórias.

Inicialmente, cada participante elaborou cinco matrizes a partir de cinco memórias diferentes. Repetimo-las individualmente com atenção na corporalização das organizações expressivas (dinâmicas, espaciais, as partes do corpo em movimento, as ações e estruturas de relacionamento) contidas em cada uma. É importante ressaltar que, nessas matrizes, as formas do corpo em movimento não compunham desenhos fixos e cristalizados, como pode ser visto nas figura 1 e 2. A precisão estava na relação entre o movimento, as imagens e os 
afetos gerados, e a energia necessária para garantir a repetição da matriz ${ }^{19}$.



O próximo passo foi ensinar e aprender as matrizes uns dos outros para elaborarmos vocabulários e imagens comuns a todos os performers. Retomamos os Estudos Coreológicos para, ao descrevermos e compartilharmos nossas matrizes, darmos indicações de dinâmicas, uso do espaço, configuração do

${ }^{19}$ Diferencio repetição de reprodução. A primeira indica realizar novamente alguma coisa e a segunda uma tentativa de se duplicar. Nesse caso, a repetição (e não a reprodução) permite, a cada realização, uma nova onda de afetos e imagens, garantindo o movimento constante de intensidades provindas da execução do movimento. 
corpo, ações e relação intra e inter corporal, ao invés de ensinar a movimentação pela forma ou por sua reprodução. Trabalhando dessa maneira, buscando repetições (e não reproduções), mantivemos as matrizes em sequências vivas, realizadas a partir de princípios de movimento que, ao serem incorporadas por cada performer, imediatamente acionavam sensações (internas) às formas corporais, as quais se externalizavam das dinâmicas corporais originárias. Após o compartilhamento e a transmissão de matrizes, começamos a ordenar, reordenar e sequenciá-las, iniciando a experimentação de possíveis estruturas dramatúrgicas.

A partir do entendimento de Bleeker (2003), de que a dramaturgia na dança é um pensamento cênico - um modo de se pensar e articular o processo pelo qual a criação acontece -, passo a considerar a dramaturgia em Memórias como um nexo intensivo, que promove a coerência no fluxo de informações entre corpo e ambiente, quando o performer em cena se utiliza de tudo o que envolve a sua presença para organizar sua atuação cênica. Tal lógica estaria no âmbito do que Dória (2016, p.202) chama de uma "dramaturgia da presença”, ou seja,

uma dramaturgia que pode ser considerada, de certo modo, abstrata e que vai além de uma compreensão intelectual, instauradora de estados emocionais que estimulava um despertar de sentidos imensamente variável para cada espectador.

De acordo com Esa Kirkkopelto (2012), a presença - o estar em cena operando o nexo de espaço, tempo, energia, imagens, sensações e afetos - é a menor unidade de atuação, uma unidade de composição que o autor chama de dramatúrgica. Para Kirkkopelto (2012, p.127)

atuação em seu sentido mais geral e esquemático significa, portanto: criar estados de ser, mantendo-os e efetuando transições entre eles, por exemplo, cirando uma composição corporal. Se uma performer cria ambos os elementos de sua atuação, por exemplo, estados de ser, e depois conecta eles de uma forma específica, efetuando transições

20 Acting in its most general and schematic sense means hence: creating states of being, maintaining them and effectuating transitions between them, i.e. creating a bodily composition. If a performer creates both the elements of her acting, i.e. states of being, and then connects them in a specific way by effectuating transitions between them, we can state that she takes the fullest possible responsibility of her creative process: she directs herself. (Tradução nossa) 
entre eles, podemos afirmar que ela assume a responsabilidade máxima de seu processo de criação: ela se dirige.

Desse modo, a atividade dramatúrgica do performer envolve seu estar em cena operando as intensidades que emergem de sua presença no espaço-tempo do processo de criação. A dramaturgia do performer implica na criação de estados de ser e a organização destes na cena. Ela não está focada sobre elementos composicionais e criativos, mas em problematizar o fluxo de informações (ou modos de se operar) entre corpo e cena (sendo esta última o espaço-tempo compartilhado com o espectador) em uma prática de se pensar em movimento.

O pensar em movimento na criação de uma obra traz a possibilidade de experimentar diferentes nexos do material criativo e suas repercussões afetivas e imagéticas. Em Memórias, o período de experimentação durou três meses (com dois encontros semanais), quando testamos associações, repetições e transformações (espaço-temporais) das matrizes, com diferentes combinações de performers atuando em cena. Investigávamos o nexo, não somente do corpo em movimento, mas também, e, principalmente, o nexo de intensidades que circulava pelos corpos a cada sequência de ações. Por fim, firmamos uma trajetória e chegamos a uma estrutura regida pelo modo como o movimento e a obra como um todo nos sensibilizava.

De acordo com a dramaturga da dança Hildegard De Vuyst (De Vuyst in Trencsényi, 2015, p.227), uma das funções do dramaturgo é cuidar da trajetória da obra, não importando se ela é dramática, pós-dramática, de dança ou teatro, sem ou com palavras. Proponho que, se os performers assumem esta função no processo de criação, como descrevi acima, eles podem ser considerados como os dramaturgos do trabalho - em uma função compartilhada entre todos os corpos-fazedores-pensantes. Assim, além da dramaturgia acontecer a partir do pensamento em movimento do coletivo de performers, ela também se dá (e, talvez, por consequência) na ordenação e estruturação da obra enquanto criação artística. Como explica a dramaturga Van Kerkhoven (2016, p.184): 
A dramaturgia tem sempre alguma coisa a ver com estruturas: trata-se de "controlar" o todo, de "pensar" a importância das partes, de trabalhar com a tensão entre as partes e o todo, de desenvolver a relação entre os atores/bailarinos, entre os volumes, as disposições no espaço, os ritmos, as escolhas dos momentos, os métodos etc.; resumindo, tradase de composição.

A dramaturgia, enquanto a composição ou estrutura de uma obra, segundo Romanska (2015), vem da teoria de Aristóteles, que descreve as estruturas do drama. Pensando na dança, Gisela Dória (Sirimarco, 2015) explica que a composição dos elementos da cena em um espetáculo de dança pode ser compreendida como sua dramaturgia. Porém, a autora faz questão de sublinhar (e exemplificar ao longo de sua tese) que cada caso sempre vai ser um caso, dependendo da linguagem e da estética utilizadas por cada artista-criador. Em Memórias, a organização das cenas e de seus elementos em uma estrutura, dependia da resposta (feedback) da experiência que os performers adquiriram na realização de cada sequenciamento e combinação experimentada.

Cada estrutura elaborada precisava ser experimentada e experienciada para, em seguida, discutirmos sobre ela. Essa experiência, imbuída de imagens, sensações e afetos particulares, nos dava pistas para a possível dramaturgia da obra. Foram um total de doze experimentações de diferentes organizações e estruturas até que chegamos à estrutura final: aquela que oferecia um nexo dramatúrgico ao que estávamos criando (imaginando, percebendo e estruturando). Essa foi uma dramaturgia criada a partir da experiência coletiva do grupo que vivenciou o processo do início ao fim. Ao contrário da criação que parte de conceitos, ideias pré-concebidas, roteiros, tema central, obra literária ou qualquer coisa que tenha surgido antes do trabalho corporal no estúdio; a dramaturgia a qual criamos foi inteiramente baseada na experiência corporal com as matrizes de movimento que, por sua vez, nasceram de memórias, ou seja, uma dramaturgia criada a partir do performer e de sua corporeidade em experimentação cênica. 


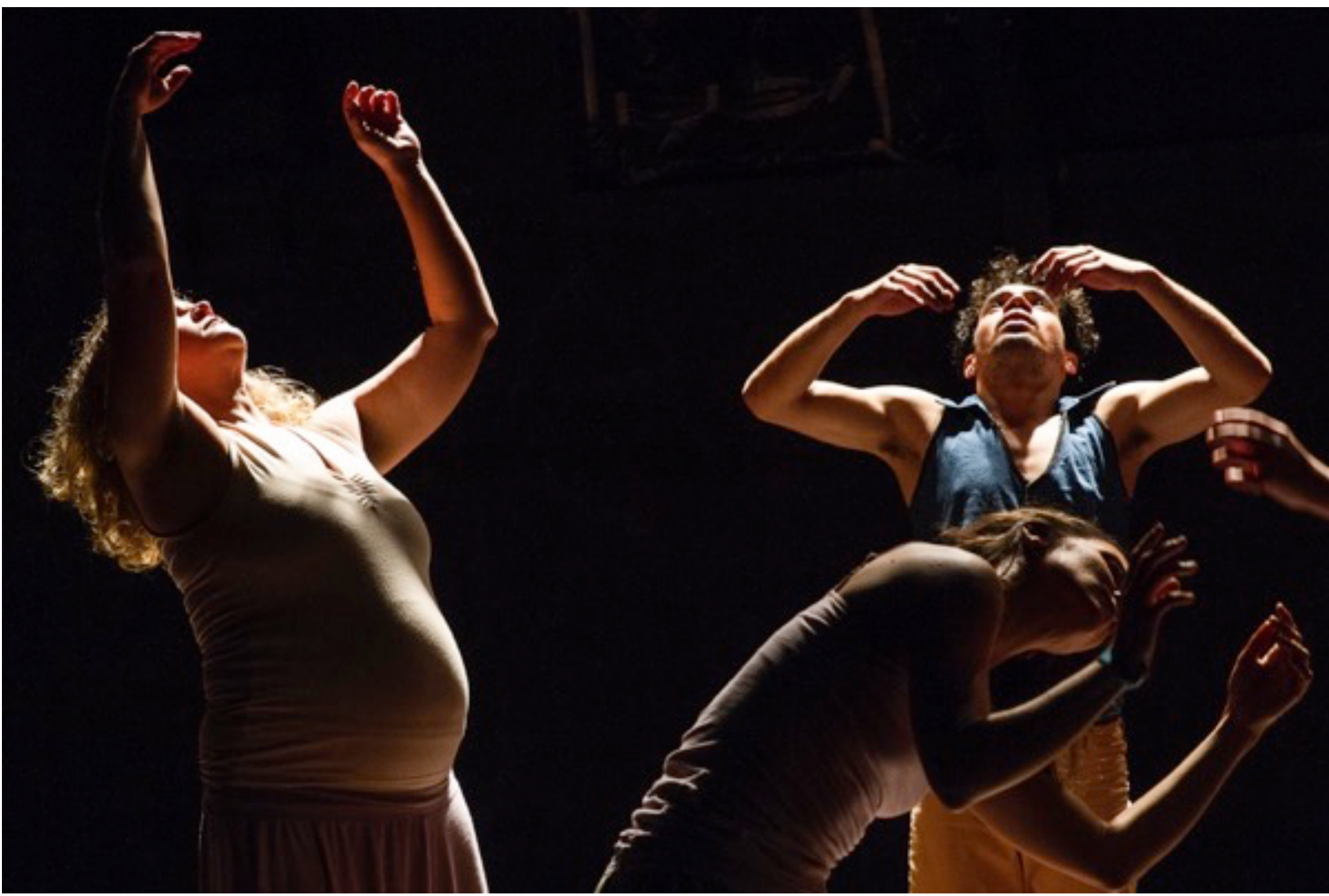

\section{Considerações finais}

Com essa experiência, concluo, concordando com a dramaturga Van Kerkhoven (2016), que a dramaturgia nas artes cênicas, além da conceituação tradicional já estabelecida, também se remete ao processo de experimentar, experienciar, ver, considerar, associar e organizar o pensamento-movimento da cena, em cena e para a cena. Tais aspectos configuram uma possibilidade de experimentação consciente, que processualmente vai se transformando na composição da cena e da obra como um todo. Uma composição que é 
consequência e não objetivo, ou seja, dependente do processo, que inicia na movimentação da corporeidade do performer, como defendida por Scialom e Fabrini (2019), e não antecipadamente visionada ou redigida como produto a ser construído. Uma dramaturgia somática que, provém de uma lógica internalizada do performer. Uma lógica que opera sobre sua corporeidade e seu estado de presença no processo de criação, podendo ser a menor unidade de composição que Kirkkopelto (2012) chama de dramaturgia, ou então uma dramaturgia da presença - como sugere Dória (2016).

Kirkkopelto (2012) reforça que a corporeidade rege o pensamento cênico do performer, sendo, portanto, determinante na criação. Dessa forma, quando o performer - como corporeidade - articula suas ações e sua presença em cena, enquanto composição, ele desenvolve uma atitude ou atividade dramatúrgica: uma dramaturgia do performer.

Neste artigo e no processo de criação que deu vida à dramaturgia do performer, procurei, através da Coreologia, exercitar o pensamento somático e cênico e, ao mesmo tempo, criar um vocabulário para o momento em que "o movimento se torna pensamento e vice-versa" em um "eterno retorno de movimento-tornando-se-pensamento e pensamento-tornando-se-movimento" (Manning, 2009, p.8) ${ }^{21}$. Erin Manning explica que, neste estado, o que surge é o entendimento de que movimento conta histórias demasiadamente diferentes das contadas pela linear e estável história. Dessa forma, acredito que o movimento (realizado pelo performer) como pensamento possibilite a criação de dramaturgias inesperadas, e, portanto, totalmente dependentes do processo criativo e da corporeidade do ator/bailarino. Assim se configura a dramaturgia do performer: uma prática que conjuga somática, pensamento cênico e composição (em um sentido amplo), em que o atuante utiliza de suas sensações e emoções, de sua dramaturgia corporal e do ator, para tensionar sua presença e sua atividade criativa.

É importante ressaltar que, apesar do termo - dramaturgia do performer já ter sido levantado por autores, teóricos e artistas, ele não foi suficientemente explorado a fim de trazer descrições do que poderia significar na prática cênica.

${ }^{21}$ eternal return of movement-becoming-thought and thought-becoming-movement. (Tradução nossa) 
Contudo, neste estudo, a dramaturgia realizada pelos performers traz a proposta de um trabalho somático na formação do artista, que contribui, para que o performer se torne dramaturgo e articulador de sua expressividade - pensando e sistematizando seu fazer através e a partir da sua corporeidade e experimentação. Desse modo, a dramaturgia do performer, além de ser dependente do processo de criação, está diretamente ligada à experiência processual do ator/bailarino. Além disso, a proposta de que a dramaturgia é uma inteligência - um pensar em movimento do intérprete-criador em busca do nexo de uma obra que nasce na sua experiência, em movimento, no processo de criação - oferece uma contribuição artística contemporânea ao fazer e aos discursos implicados nos estudos da dança, do teatro e da dramaturgia em geral, incitando futuras investigações no campo das artes cênicas e do movimento como um todo.

\section{Referências}

ABREU, Luís Alberto de. O dramaturgo e suas funções. Rebento, São Paulo, v. 2, p.26-31, 2010.

BARBA, Eugenio. On directing and dramaturgy: burning the house. London; New York: Routledge, 2010.

BERNARD, Michel. De la création chorégraphique. France: Centre national de la danse, 2001. (Recherches).

BITTENCOURT, Adriana. Imagens como acontecimentos: dispositivos do corpo, dispositivos da dança. Salvador: EDUFBA, 2012.

BLEEKER, Maaike. Dramaturgy as a Mode of Looking. Women \& Performance: a journal of feminist theory, [s. l.], v. 22, n. 13:2, p.163-173, 2003.

BONFITTO, Matteo. O ator-compositor: as ações físicas como eixo: de Stanislávski a Barba. São Paulo, SP, Brasil: Editora Perspectiva, 2002.

CAETANO, Patricia Lima. Pistas somáticas para um estudo da corporeidade: uma aprendizagem das sensações. Fractal: Revista de Psicologia, [s. l.], v. 29, n. 2, p.168-176, 2017.

CALDAS, Paulo; GADELHA, Ernesto (org.). Dança e Dramaturgia[s]. Fortaleza: Nexus, 2016. 
COOLS, Guy. Sobre Dramaturgia da Dança. Revista Cena, Porto Alegre, v. 29, p.5354, 2019.

CURI, Alice Stefânia. Dramaturgias de Ator: puxando fios de uma trama espessa. In: CURI, Alice Stefânia; MELLO, Mônica; CASTRO, Rita de Almeida (org.). Poéticas do corpo: instantes em cena. Brasília: Editora UNB, 2017. p.19-34.

DELAHUNTA, Scott. Dance Dramaturgy: speculations and reflections. Dance Theatre Journal, [s. l.], v. 16, n. 1, p.20-25, 2000.

DELEUZE, Gilles; GUATTARI, Felix. A thousand plateaus: capitalism and schizophrenia. London: Continuum, 2004.

DÓRIA, Gisela. Entrelaçando Fios: possíveis eixos dramatúrgicos na Dança Contemporânea. Art Research Journal/Revista de Pesquisa em Arte, Natal, v. 3, n. 2, p. 94-208, 2016.

EDDY, Martha. Mindful movement. the evolution of the somatic arts and conscious action. Chicago, IL: Intellect/University of Chicago Press, 2017.

FALKEMBACH, Maria. O Corpo na Composição do Drama. Revista Cena, Porto Alegre, n. 6, 2009.

FERNANDES, Ciane. O corpo em movimento o sistema Laban/Bartenieff na formação e pesquisa em artes cênicas. 2nd. ed. São Paulo: Annablume, 2006.

FERNANDES, Ciane. Pesquisa Somático-Performativa: Sintonia, Sensibilidade, Integração. Art Research Journal/Revista de Pesquisa em Arte, [s. l.], v. 1, n. 1, p.76-95, 2014.

FERRACINI, Renato. Ação Física: Afeto e Ética. Urdimento - Revista de Estudos em Artes Cênicas, Florianópolis, v.2, n.13, p. 123-134, 2009.

GIL, José. Movimento Total o Corpo e a Danca. São Paulo: Iluminuras, 2018.

GREINER, Christine. O corpo: pistas para estudos indisciplinares. São Paulo: Annablume, 2005.

HANNA, Thomas. Corpos em Revolta. 2a. ed. [S. l.]: Mundo Musical, 1976.

HANNA, Thomas. What is Somatics. Journal of Behavioral Optometry, [s. l.], v. 2, n. 2, p. 31-35, 1991.

HANSEN, Pil. Introduction. In: HANSEN, Pil; CALLISON, Darcey (org.). Dance dramaturgy. modes of agency, awareness and engagement. Houndmills, Basingstoke Hampshire; New York, NY: Palgrave Macmillan, 2015. 
HODGSON, John. Mastering movement: the life and work of Rudolf Laban. London: Methuen, 2001.

KIRKKOPELTO, Esa. An actor never deals with elements smaller than a world. In: How Performance Thinks. An International Conference Co-Organised by the PSi Performance \& Philosophy Working Group and Kingston University's Practice Research Unit, Studio Centre, Londres, Reino Unido, p. 123-128, 2012.

LABAN, Rudolf von. A life for dance: reminiscences. London: Macdonald \& Evans, 1975.

LABAN, Rudolf von. Choreutics. London: Macdonald \& Evans, 1966.

LABAN, Rudolf von. Domínio do Movimento. Sao Paulo: Summus, 1978.

LEHMANN, Hans-Thies; PRIMAVESI, Patrick. Dramaturgy on Shifting Grounds. Performance Research, [s. l.], v. 14, n. 3, p. 3-6, 2009.

MACEDO, Vanessa; PEREIRA, Sayonara. Caminhos que pensam a dramaturgia em rede. In: II CONGRESSO NACIONAL DE PESQUISADORES EM DANÇA, 2012. Anais do /l Congresso Nacional de Pesquisadores em Dança - Anda. [S. l.]: ANDA, 2012. p. 1-12.

MALETIC, Vera. Body, space, expression: the development of Rudolf Laban's movement and dance concepts. Berlin; New York: Mouton de Gruyter, 1987.

MANNING, Erin. Relationscapes: movement, art, philosophy. Cambridge, Mass.: MIT Press, 2009. (Technologies of lived abstraction).

MOKOTOW, Anny. Decentring dance dramaturgy - a proposition for multiplicity in dance. In: WORLD DANCE ALLIANCE GLOBAL SUMMIT, 2014, Angers, France. Contemporising the past: envisaging the future. Angers, France: [s. n.], p. 1-10, 2014.

NELSON, Robin. Practice as research in the arts: principles, protocols, pedagogies, resistances. Basingstoke: Palgrave Macmillan, 2013.

NEVES, Neide. Klauss Vianna - estudos para uma dramaturgia corporal. São Paulo: Cortez, 2008.

NEWLOVE, Jean. Laban for actors and dancers: putting Laban's movement theory into practice, a step-by-step guide. London: Nick Hern Books, 1993.

PAVIS, Patrice. Dicionário de teatro. São Paulo, Brasil: Perspectiva, 2008.

PIZARRO, Diego. Anatomia Corpoética Em De(composições). Três Córpus de Práxis Somática em Dança. 2020. Tese (Doutorado) - Universidade Federal da Bahia, Salvador, 2020. Disponível em: https://repositorio.ufba.br/ri/handle/ri/32962. Acesso em: 2 maio 2021. 
PIZARRO, Diego; VILELA, Lilian Freitas. Somática e dança como campos de intensidades relacionais. In: CUNHA, Carla Sabrina; PIZARRO, Diego; VELLOZO, Marila Annibelli (org.). Práticas Somáticas em Dança: Body-Mind Centering em Criação, Pesquisa e Performance. Brasília, DF: Editora IFB, 2019. (Coleção Práticas Somáticas em Dança). v. 1, p. 15-26.

PRESTON-DUNLOP, Valerie. Rudolf Laban: an extraordinary life. London: Dance Books, 1998.

PROFETA, Katherine. Dramaturgy in motion: at work on dance and movement performance. Madison, Wisconsin: The University of Wisconsin Press, 2015. (Studies in dance history).

ROMANSKA, Magda (org.). The Routledge companion to dramaturgy. London; New York: Routledge, 2015.

SCIALOM, Melina. Experimentando a Dramaturgia do Performer. Memória Abrace, [s. l.], v. 19, n. 1, p. 1-13, 2019.

SCIALOM, Melina. Os Estudos Coreológicos como Práxis para Construção de uma Dramaturgia Afetiva. Revista Cena, Porto Alegre, v. 12, p. 9-17, 2020.

SCIALOM, Melina; FABRINI, Vêronica. Dramaturgia na dança: manipulação de energia no processo. Revista Cena, Porto Alegre, v. 29, p.2-13, 2019.

SHOUSE, Eric. Feeling, Emotion, Affect. M/C Journal, [s. l.], v. 8, n. 6, 2005. Disponível em: <http://journal.media-culture.org.au/0512/03-shouse.php>

SILVA JÚNIOR, Ireno Gomes da; MACHADO, Adriana Bittencourt. A imagem do corpo na dança como dispositivo de afeto. Brazilian Journal of Development, [s. l.], v. 6, n. 7, p.45762-45770, 2020.

SIRIMARCO, Gisela Dória. (De)Composição e Produção de Sentido: Dramaturgias na Dança Contemporânea. 172 f. 2015. Tese (Doutorado) - Universidade Estadual de Campinas, Campinas, SP, Brasil, 2015.

SOUZA, Elisa Teixeira de. Embodiment (Corporalização), Soma e Dança: alguns nexos possíveis. Revista Brasileira de Estudos da Presença, Porto Alegre, v. 10, n. 4, p.1-30, 2020.

TRENCSÉNYI, Katalin. Dramaturgy in the making: a user's guide for theatre practitioners. London; New York: Bloomsbury, 2015.

TURNER, Cathy. Getting the 'Now' into the Written Text (and vice versa): Developing dramaturgies of process. Performance Research, [s. l.], v. 14, n. 1, p. 106-114, 2009. 
TURNER, Cathy; BEHRNDT, Synne K. Dramaturgy and performance. Basingstoke; New York: Palgrave Macmillan, 2008. (Theatre and performance practices).

VAN KERKHOVEN, Marianne. O processo dramatúrgico. In: CALDAS, Paulo; ERNESTO GADELHA (org.). Dança e Dramaturgia[s]. Fortaleza: Nexus, 2016.

VARGAS, Vagner De Souza; BUSSOLETTI, Denise Marcos. Dramaturgia da corporeidade do ator: Proposta e Reflexões. Revista Digital do LAV, [s. l.], v. 8, n. 4, p. 65-87, 2015.

Recebido em: 20/12/2020

Aprovado em: 05/07/2021 